\title{
Innovating the Maintenance Repair and Overhaul Phase through Digitalization
}

\author{
Marco Esposito 1,,$+ * \mathbb{D}$, Mariangela Lazoi ${ }^{1,+}$, Antonio Margarito ${ }^{1,+}$ and Lorenzo Quarta ${ }^{2,+}$ \\ 1 Department of Innovation Engineering, University of Salento, 73100 Lecce, Italy; \\ mariangela.lazoi@unisalento.it (M.L.); antonio.margarito@unisalento.it (A.M.) \\ 2 Naica Società Cooperativa, 73100 Lecce, Italy; lorenzoquarta@naicasc.com \\ * Correspondence: m.esposito@unisalento.it; Tel.: +39-3285356888 \\ + These authors contributed equally to this work.
}

Received: 28 March 2019; Accepted: 7 May 2019; Published: 9 May 2019

\begin{abstract}
Improving processes in a company starts from a deep knowledge of the current context, of the needs for improvement and of the objectives to be satisfied. Sometimes, traditional processes can benefit from a techno-organizational innovation that changes the way of work by introducing new routines and solutions. The service industry related to maintenance, repair and overhaul (MRO) is characterized by performance linked with the knowledge about the components involved. The emerging technologies and the need for enhanced competitiveness has led to transform and innovate this kind of industry, introducing changes in organizational and technological aspects. MRO processes are characterized by high variability, caused by the uncertainty about the arrival status of a part to be maintained and the intervention needed. The management of MRO processes is, thus, one of the most important challenges for the research community. This paper aims to describe the result of a study carried out by university researchers and industrial engineers of an aerospace company. The proposed solution, the applied approach and expected impacts and benefits are described in the paper in order to lead future activities in the managerial and academic fields.
\end{abstract}

Keywords: MRO; RFID; tracking; parts; knowledge management; aerospace industry

\section{Introduction}

In the last few years, the global airline industry has produced strong financial results due to different factors. Oliver Wyman's 2016-2017 Airline Economic Analysis [1] highlighted that the major growth of the engine market will be in Asia, especially China and India, which will become the largest region, nearly doubling in-service fleet and related maintenance, repair and overhaul (MRO) demand. Furthermore, the significant increase in retirements will continue to fuel the growing used serviceable material (USM) market, which has the potential of reducing material costs for airlines and MROs.

Over the next decade, each of the fleet complexities translates to significant changes and challenges for the MRO industry. Commercial airline MRO growth will be healthy at $3.8 \%$ compound annual growth rate (CAGR) over the 10-year period, growing from the current demand of $\$ 75.6$ billion to just over $\$ 109$ billion by 2027 [2].

In the next years, in the view of increasing profitability of the MRO activities, the $73 \%$ of companies offering MRO services (1236 surveyed companies interviewed through an online questionnaire [3]) aim to enhance the reliability of the products undergoing MRO activities and $64 \%$ aim to increase the efficiency of resources involved in such processes The surveyed providers are aligned in considering their high level of specialization as the predominant criterion for customers to choose their company, together with the advance in knowledge regarding the performance of the MRO activities [4]. 
Business processes optimization is increasingly linked to the application of methodologies and technologies of the "Smart Factory" paradigm. In recent years, the development and consolidation of new enabling technologies in the industrial world, like mobile internet, automation of knowledge work, Internet of Things, cloud computing, additive manufacturing and others identified in various research studies, has fostered an acceleration of the process of change [5]. Increasing pressures, induced by the global competition, are forcing the world of industrial production to answer to the needed transformation.

The nature of the traditional manufacturing industry could be deeply transformed through a closer integration of such new technologies into industrial processes. To pursue this objective, these technologies also have to be integrated with the already existing information systems of a company, e.g., product lifecycle management (PLM) systems for the product data management, enterprise resource planning (ERP) systems for sales, purchase, warehouse and accounting activities management, manufacturing execution systems (MES) dedicated to manufacturing operations management, etc. Only when these technologies will allow the development of a distributed intelligence, structured in a network of assets, able to provide the interaction between real-world objects and virtual ones, will it be possible to speak of "Smart Factory".

This new aspect is crucial for the development and manufacturing of complex products because such processes are complicated by some difficulties: In particular, these difficulties can be seen when dealing with compliance and alignment between the development state of a physical object and its related virtual information, which are managed by the enterprise through PLM, ERP and/or MES systems [6]. Furthermore, the increasing product complexity requires a better integration of the different knowledge domains of companies located in the firm's value network [7], together with an accurate and punctual data management system.

The MRO (maintenance, repair and overhaul) business is one of the most interesting for manufacturing companies. MRO could be defined as "all actions that have the objective of retaining or restoring an item in or to a state in which it can perform its required function. The actions include the combination of all technical and corresponding administrative, managerial and supervision actions" [8]. For these reasons, it is possible to say that MRO processes are extremely hard to manage. Such a difficulty is due both to the high specialization level requested in managing increasingly complex products and to the need to operate in compliance with national and international regulations and laws [9]. Furthermore, MRO processes are characterized by high variability, due to the uncertainty about the status of the engine to be maintained: The activities to carry out are set according to the engine arrival conditions and the needed type of intervention [4]. Management of such a variable process is, hence, one of the most important challenges that the Information and Communications Technology (ICT) systems have to face in supporting the management. To get work-in-progress (WIP) information from the shop floor (accurate and up-to-date information about the (physical) parts constituting engines and components, regarding both their localization, their identification data such as part number, serial number, quantity, job order, etc.) and their processing status is of great importance. The systematic availability of such information allows the enterprise to have an improved control on work order and process activities [10].

Starting from previous assumptions, the University of Salento in partnership with an aerospace company carried out a research project. The aim was to innovate organizational practices through the introduction of a technological solution influencing industrial practices and data availability, through a knowledge management system aimed to make available the work-in-progress knowledge throughout the MRO processes and to all the actors involved. The addressed research question was "How can the MRO process be enhanced through an innovative work-in-progress knowledge management system?" The proposed solutions was based on a structured research methodology developed and applied for addressing the specific needs of the industrial context. The results enlarge the state of art about business processes management case studies, highlighting technologies and impacts and addressing best-practices for the study's replication. 
The paper has three main sections: A theoretical background that provides definitions and describes the linkage with the available literature; a research method, which provides more details about the research phase; and a results section that treats organizational and technological innovation and the related impacts and benefits. Finally, the conclusions of the research are presented at the end of the paper.

\section{Theoretical Background}

The increasing global competition and the development and consolidation of new enabling technologies fostered the process of change in the international industrial scenario. The Industry 4.0 paradigm implementation is a necessary step towards the growth of businesses and the clue is the digitalization of processes and data [11]. The scope is to implement new technologies in processes, in order to create an organic and continuous stream of data running through the different levels of the supply chain, facilitating the communication between the stakeholders and accelerating the process of innovation.

Digital Factory currently represents the most progressive paradigm change in both research and industry, covering the complex, integrated design of products, production processes and systems [12].

The digitalization of a factory enables the real time analysis and usage of all information coming from the different phases of product lifecycle, properly aggregated to give sensitive data to control and enhance processes: Reliability of machinery, needs from the target market, criticalities and bottlenecks in processes, parts flows, etc. It is very important to gain all the required data only one time and then to manage them with uniform data control, so that all software systems will be able to utilize it. The integration is one of the main conditions for the implementation of Digital Factory [13]. Knowledge management should focus on knowledge integration (KI) instead of focusing on simple knowledge transfer, in order to combine different knowledge elements and develop new skills $[14,15]$.

The increasing availability of information is the source of criticalities in process management, since the time for the analysis of such an amount of data is instead decreasing. For that reason, one of the typical manufacturing data distribution applications is the real-time production status monitoring and data collection [16], continuously updating the enterprise systems. The so-called work-in-progress (WIP) knowledge has a critical importance in the management of processes. Through WIP knowledge, manufacturers can see which products are entering various phases of production in real time and this enables managers to make strategic decisions that improve efficiency and reduce costs [10].

Beside the WIP knowledge, manufacturing companies need traceability, which is a real-time view into their operations and processes. Traceability helps manufacturing enterprises to ensure compliance with government regulations, and to perform rapid, focused and cost-effective product tracking along the whole product lifecycle [17], through an exhaustive WIP knowledge utilization.

The International Standardization Organization (ISO), through the ISO 8402-94 ("Quality Management and Quality Assurance Vocabulary") defines traceability as "The ability to trace the history, application or location of an entity by means of recorded identifications". In discrete manufacturing industry, traceability means that each part and component have to be traced throughout the whole lifecycle, from design to delivery, in order to create an "as built" genealogy of product configuration. Manufacturing companies look at traceability as a real-time view into their production processes and operations [17]. In order to make product management more efficient during the whole life cycle, data collection about all kinds of flows of products, materials, parts/subassemblies and dangerous elements/materials is of crucial importance [16]. 
The identification of the most appropriate tracking technology depends on the type of data to be collected and related enterprise processes. Based on data, parts to be traced, process features and tasks, depending on the involved professionals, adopted technologies and ICT supporting systems, it is possible to design a solution able to properly deliver data to each stakeholder involved in the operation. Therefore, it is necessary to know exactly when data are generated, used and modified and why this happens. The application of business process management (BPM) to model processes ensures the enhancement of operational standards and simplicity in managing data [18]. Any kind of process can be optimized using BPM techniques.

Among all, the MRO processes, especially those concerning unplanned maintenance, seem more variable than the production processes. MRO related activities are not always fixed, but they depend on the arrival conditions of engines and components, hence the "job scope" or "work scope" of repairing is not predictable a priori. The importance of $\mathrm{MRO}$ processes lies in the profitability of the aviation industry, which is not from the sale of aircraft, but from ensuring their reliability through maintenance for a lifespan of thirty-plus years [19], thereby companies providing MRO services strive to minimize maintenance costs and turn-around time with the aim of maximizing revenue. The utilization of PLM in such processes can potentially lower costs and time [20], however, the integration of PLM with MRO processes is nearly ten times less frequently in comparison with the aircraft design phase [21]. One of the possible reasons is the lack of PLM systems properly designed and implemented for supporting product maintenance or service tasks [22].

$\mathrm{MRO}$ in aviation requires obtaining product and processing knowledge in order to optimize time and quality of maintenance [21]. Such knowledge is not always accessible and can be difficult for users to search and get the right information quickly, and this leads to delays in delivery [23]. Therefore, it is of great importance to have the chance to get, from the shop floor, accurate and up-to-date information about the (physical) parts constituting engines and components, regarding both their localization and their processing status. Work-in-progress (WIP) tracking guarantees the systematic availability of such information and this allows the enterprise to have an improved control on work order and process activities. It is furthermore significant to have widespread coverage of product information and work orders along the whole shop floor, by reporting data with accuracy and promptness in order to allow process execution as quickly and efficiently as possible [24]. The real-time availability of WIP knowledge is currently a common need for smart manufacturing enterprises. The limitation of using bar-coding based technology [25] and the dropping cost of RFID (Radio-Frequency Identification) technology have motivated the research for RFID-based technology in the field of advanced manufacturing technology (AMT), which relies substantially on wireless devices and wireless information networks for the collection and synchronization of the real-time field data from manufacturing workshops, replacing the paper-based manual WIP tracing [26]. The scope is to enable the transfer of production line data to the enterprise-based systems. This may result in quicker improvement of the entire "product quality assurance" process by decision makers, updated workflow charts, and inspection procedures delivered to the proper worker groups via digital displays in real time. The knowledge involved in MRO services can be associated to product-service knowledge, because it describes the functions and the processes of MRO services, as well as the components where the service occurs [27]. According to the MRO process classification stated by Zhu et al. [28], the reference knowledge plays a crucial role in evaluating MRO performance, because it comprehends historical data and WIP knowledge. 
Many research studies have demonstrated the adequacy of RFID technology in process management, like in parts and assets trace and tracking [29], supply chain management [30], WIP tracking [26] and resources management in aerospace maintenance operations [31]. The MEERA project (Mobile Enabled Engine Repair Application), implemented in 2012 by TAP Maintenance and Engineering, in collaboration with Airbus Megasys, has been the first fully operational project ever, regarding RFID application to aerospace engine components, in a MRO context. In particular, the aim was to enable the traceability of tools and ground support equipment (GSE) and monitor the transportation of GSE between different buildings, in order to enhance the inventory system and to overcome the limits in reporting and verifying toolboxes contents. The MRO process and the related information systems used to support its activities are widely addressed in different studies. Zhu et al. [28], proposed a Web-based product service system (PSS) to manage MRO within three different perspectives (service, use and result) in order "to better integrate the product development process with associated maintenance and service processes". Furthermore, they classified the knowledge involved in MRO services into different levels and arranged it in a hierarchical model for the unambiguous reuse of such knowledge.

Geng et al. [32] proposed a new model of MRO job card based on a three-dimensional (3D) model of a product and using model based definition (MBD) technology [33]. The research suggested a method for 3D MRO job card designing, a new and more intuitive and complete MRO job card model, which integrated MRO process description and a lightweight assembly model, with the objective to improve MRO quality and efficiency.

The impact of PLM on MRO processes is thus considerable [21] but the management of related knowledge is still an open issue and many research studies are addressing it both from a technological and from a methodological point of view.

\section{Research Design}

This paper aims to provide guidelines for a techno-organizational solution oriented to improve the management of information related to the activities and parts involved in the MRO process of aeronautical components that need to be digitalized both in the activities and in the information flow, in order to reduce errors, improve quality and speed-up execution time. This research is part of the Italian research project called SPIA (i.e., Innovative Aeronautic Supporting Structure) that aims to achieve a radical improvement in the manufacturing process performance through design, implementation and field test of methodologies and technologies, linked to the Smart Factory paradigm. One of the main objectives is the optimization of concurrent and collaborative business processes and the development of ICT tools, able to strengthen the collaboration between the shop floor and the engineering company departments of design and production.

Based on the cited premises, on the relevance of the MRO process and on the theoretical background described, an action research was realized in collaboration between a team of university researchers and an aerospace company's actors involved in the MRO processes for aeronautical components. A core team composed by two researchers and a company information technology (IT) leader managed the overall study and collaborated with other relevant key-users along the overall study. The researchers played a role of direct participant in the study of the industrial context and strictly collaborated with the company's engineers.

Five main research phases were performed in the execution of this study (Table 1).

Direct observation, finally, was a further method used to collect information and feedback. Members of the core team observed the company practice, visited the shop floor to visualize the described processes, and looked at the solutions usage and the criticalities in its working. They took notes and guided the research activities whilst also integrating this information.

Therefore, a wide set of competencies were developed during this research and the main results are reported in the next section together with general implications for further replication. 
Table 1. Research phases of the study.

\begin{tabular}{|c|c|c|c|}
\hline Phase & Description & Method & Main Contribution \\
\hline $\begin{array}{l}\text { Innovation } \\
\text { Statement }\end{array}$ & $\begin{array}{l}\text { The needs for research and innovation are defined } \\
\text { discussing the main context in a focus group with } \\
\text { key-users of the company and researchers } \\
\text { confident with the analyzed domain. In this phase, } \\
\text { the critical sub-processes are selected and the main } \\
\text { features are defined (linkage among sub-processes, } \\
\text { constraints, enablers and main input and output). }\end{array}$ & $\begin{array}{l}\text { Open-ended } \\
\text { interviews, focus } \\
\text { group, daily } \\
\text { meetings }\end{array}$ & $\begin{array}{l}\text { Requirements of } \\
\text { innovation, } \\
\text { sub-processes } \\
\text { definition }\end{array}$ \\
\hline $\begin{array}{c}\text { Sub-Processes } \\
\text { Analysis }\end{array}$ & $\begin{array}{l}\text { Sub-processes are modeled with different review } \\
\text { cycles involving experts at different levels. The } \\
\text { final result is represented by a set of sub-processes } \\
\text { commonly agreed in the flow of activities, data and } \\
\text { information and systems involved in each task. }\end{array}$ & $\begin{array}{l}\text { Open-ended } \\
\text { interviews, direct } \\
\text { observation, daily } \\
\quad \text { meetings }\end{array}$ & $\begin{array}{l}\text { As-is process } \\
\text { modelling }\end{array}$ \\
\hline $\begin{array}{l}\text { Organizational } \\
\text { Feedback }\end{array}$ & $\begin{array}{l}\text { The designed processes are analyzed in order to } \\
\text { identify bottlenecks, problems, loss of information } \\
\text { and IT (information technology) systems with low } \\
\text { performance. The results of this phase are } \\
\text { guidelines in the processes execution and the } \\
\text { definition of desired processes to be implemented. }\end{array}$ & $\begin{array}{l}\text { Focus group, daily } \\
\text { meetings }\end{array}$ & $\begin{array}{l}\text { To-be (desired) } \\
\text { processes, definitions } \\
\text { of issues to be } \\
\text { managed }\end{array}$ \\
\hline $\begin{array}{l}\text { Technological } \\
\text { Development }\end{array}$ & $\begin{array}{l}\text { Organizational innovation needs often a } \\
\text { technological solution for enabling the required } \\
\text { change and lead better performance. Based on this } \\
\text { consideration, a technological solution is designed } \\
\text { and implemented preceded by a benchmark of } \\
\text { commercial software to be used. The result of the } \\
\text { benchmark has been used to lead the IT designers } \\
\text { for the definition of a technological solution } \\
\text { enabling the desired processes. }\end{array}$ & $\begin{array}{l}\text { Open-ended } \\
\text { interviews, daily } \\
\text { meetings }\end{array}$ & Solution prototype \\
\hline Validation & $\begin{array}{l}\text { The potentialities of the technological solution and } \\
\text { the required organizational changes have been the } \\
\text { object of evaluation for gathering feedback about } \\
\text { the working principles and the users' acceptance. }\end{array}$ & $\begin{array}{l}\text { Direct observation, } \\
\text { focus group, daily } \\
\text { meetings. }\end{array}$ & $\begin{array}{l}\text { Benefits, lesson } \\
\text { learned, impacts }\end{array}$ \\
\hline
\end{tabular}

\section{Results: Steps toward Digitalization}

\subsection{The Analyzed Business Domain}

Generally, one of the main problems in highly variable and unpredictable processes, such as MRO process (maintenance, repair and overhaul) in the aerospace sector, is to maintain a good alignment between process data available in company information systems and the current state of the process in the shop floor. This misalignment is mainly due to the not easily automatable nature of this kind of industrial process: State advances in the MRO process are made by users who record the operations into the enterprise systems.

To respond to the complexity of managing these processes and to achieve a radical improvement in performance, companies have begun to use innovative technologies for the identification and automatic tracking of physical objects. These technologies, enabling the adoption of Internet of Things paradigms in industry, allow companies to establish a bridge between information stored in business systems and the actual data. The presence of this bridge allows better alignment of information to the real world, bypassing the manual input insertion made by users.

For the case under consideration in this study, the problem was similar: Providing greater accuracy on the position of the engine parts under review and on the working state of these parts. Proper tracking of the parts inside the plant is critical for any company that carries out MRO activities.

To address this problem, business processes were analyzed in the company plant. For each analyzed process, the following information were specified: 
- Activities flow

- Actors involved in each task/process

- Supporting technologies and information systems used to carry out process activities

- Information required by the operators or systems involved for the correct execution of tasks

Such information was collected and systematized in process models diagrammed according to the Business Process Modeling Notation (BPMN) [34].

Considering all the analyzed processes around MRO, the process of Inefficient Articles Revision was chosen for a detailed study (Figure 1). It is composed of more than eighty different activities distributed in the sub-processes illustrated in the following schema:

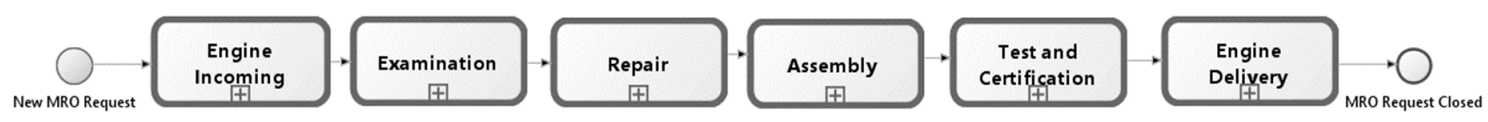

Figure 1. The main sub-processes of Inefficient Articles Revision process.

All the described activities were supported by the corporate legacy manufacturing execution system (MES) that manages the production activities related to the execution of the work orders (i.e., task, time, resources ... ) and also, the product structure and the product under repair master data (i.e., part numbers, serial numbers, quantities, etc.). Furthermore, it interfaced with the company's ERP for the retrieval from the warehouse of replacements for non-repairable parts and a direct link with machines for gathering useful information to be used to monitor all the production lines.

The AS-IS process models, derived from the analysis, enabled a greater understanding of the flow of activities, professional roles involved, needed data, and tools used to support the various activities for the MRO process.

The modelled processes were used to define the detailed requirements for the new technological solution and to specify the main elements for a benchmarking of commercial technological solutions to be used and/or integrated to reach the final results. Furthermore, the impacts of different technologies on the execution of processes were defined and tested based on the designed activity flows.

\subsection{Technological Features and Components}

There are growing needs in companies to access data from manufacturing/service areas in order to maximize production or maintenance capacity. In this sense, the identified technology and designed software architectures strongly make the difference in benefits and achieved results. In our case, the most important requirement considered in the design phase of the solution was the accuracy in part tracking and identification. Identifying almost all the objects on the pallets was the main goal of the approach. The proposed concept was to link, through the technology, all the different devices to gather all the information about tracking in a single and integrated ICT system in order to support the MRO process.

The research started with the state-of-art evaluation, carried out through the study of scientific literature regarding the most important automated identification technology (AIT) for the realization of advanced management systems. Different tracking technologies were identified (RFID, UWB (Ultra-Wide Band), Beacon, RuBee). A benchmark of such technologies had been performed based on the company's business requirements: Reading reliability (\#1), locating system (\#2), unique tag identification (\#3), middleware interoperability (\#4), impact resistance (\#5), internal memory (\#6), technology cost (\#7), technology maturity (\#8). To resume the evaluation of tracking technologies, a Likert scale from 1 (weak) to 5 (strong) has been used in this study, considering a specific weight for each requirement (evaluated in accordance with the company). The result of the benchmark is shown in Table 2. 
Table 2. Tracking-technology benchmark.

\begin{tabular}{cccccc}
\hline \#Business Requirement & Weight & RFID & UWB & Beacon & RuBee \\
\hline \#1 Reading Reliability & 3 & 4 & 5 & 1 & 5 \\
\#2 Locating System & 2 & 3 & 4 & 2 & 4 \\
\#3 Unique Tag Identification & 3 & 5 & 4 & 5 & 5 \\
\#4 Middleware & 3 & 5 & 5 & 3 & 3 \\
Interoperability & 1 & 5 & 5 & 5 & 5 \\
\#5 Impact Resistance & 1 & 4 & 5 & 4 & 4 \\
\#6 Internal Memory & 3 & 4 & 2 & 4 & 2 \\
\#7 Technology Cost & 2 & 5 & 2 & 3 & 4 \\
\#8 Technology Maturity & & 79 & 70 & 58 & 70 \\
TOTAL & & & & & \\
\hline
\end{tabular}

The results of such research gave the ability to choose the RFID as the most proper technology to work with. This technology allows storing and retrieving data through the transmission and reception of electromagnetic waves to an integrated circuit compatible with these radio frequencies and is now considered as the best solution to improve the data tracking management process. An RFID system consists of several basic elements, such as a reader, antennas, transponders or RFID tags or labels, and protocols and methods of communication, and an information management system for the transfer of data given to and from readers.

Once the RFID solution feasibility was proved and the optimal configuration was identified, the other components of the supporting ICT system were designed and developed: A database to store tracking data, a printer gateway service, an RFID middleware solution, a set of micro-service to read/write (R/W Microservice) data from the database and from enterprise systems, a mobile application. In particular, interface services necessary to retrieve information from the MES system were designed: Product engineering information, in fact, is commonly available in companies' product lifecycle management systems and a subset of information necessary to the shop floor to perform the repair activities was transferred to the MES system.

To enable the tracking process, the affected items needed to be identified and classified with a label containing the RFID tag. The printer gateway was a service that integrated with the corporate management system, allowed the printing of labels with an RFID circuit containing all the metadata (e.g., product model; engine number; part number $(\mathrm{P} / \mathrm{N})$; serial number; name; quantity; work order code, efficiency state, entry date, delivery date, revision number, catalogue number, figure number) of the specific item.

A set of read/write micro-service (R/W Microservice) was built according to the micro-service software architecture, which enables read and write access to the system database. The database represented the data model at the base of the tracking process. The R/W Microservice acted as an interface between the database and one of the core components of the system in analysis, the middleware.

Furthermore, the middleware communicated with a mobile application. This one was based on an Android operating system, provided multichannel access to data with a business authentication system (OAuth 2.0 and SSL (Service Sockets Layer) based SSO (Single Sign-On services)). The application acted as a proximity reader (RFID reader) extension that allowed the detection of "scattered" RFID tags in the factory. The application was designed to be highly usable and the data was presented to be used immediately. For better support the understanding of the implemented solution, all the described elements are graphically represented in the functional architecture in Figure 2. 


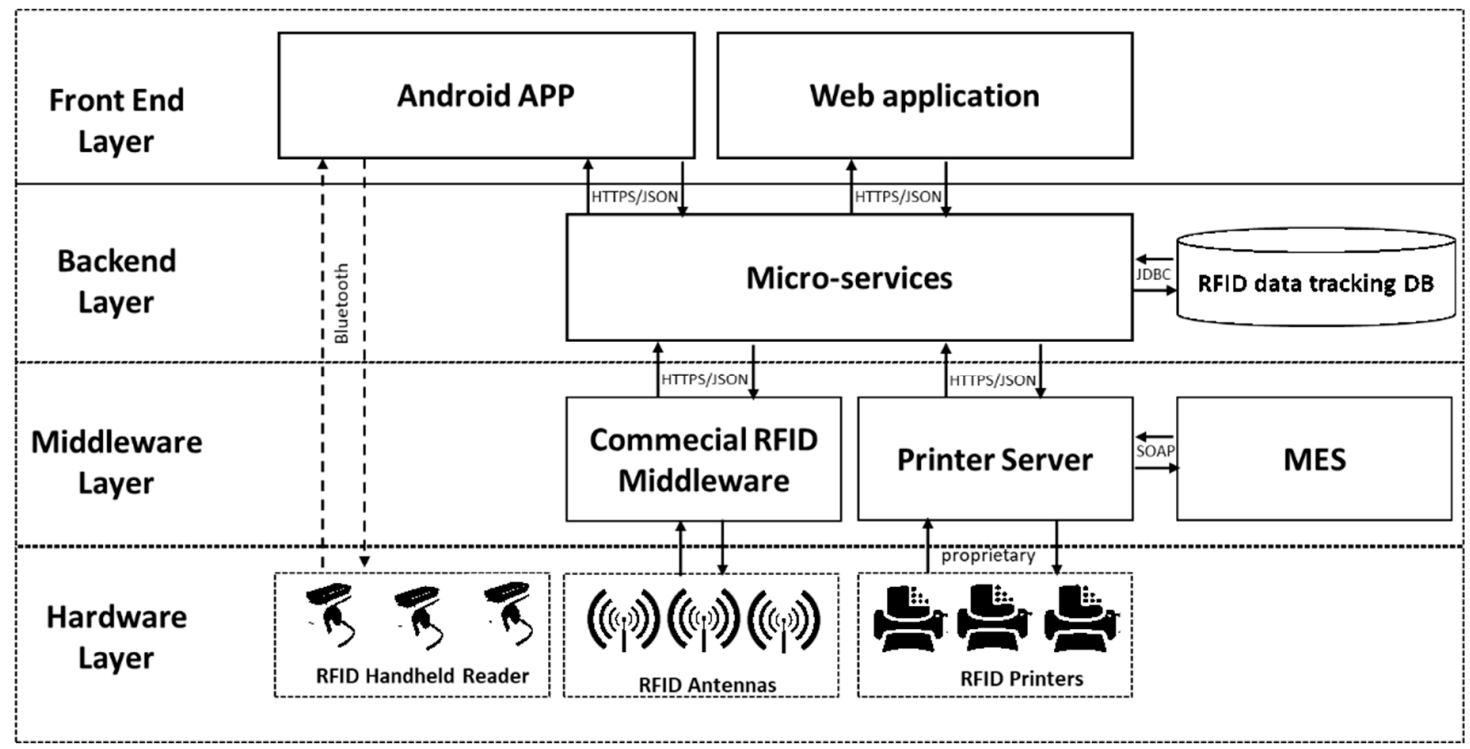

Figure 2. Functional architecture.

All components of the new tracking system were developed in an easily customizable way:

- A single database for recording parts tracking data developed with a minimum set of general information;

- Services for querying the database (read and write) were specified and implemented as RESTful services (Representational State Transfer-software architectural styles defining constraints to be used for creating Web Services), developed according to a micro-service approach, for data exchange between mobile application, middleware integration service and the database;

- A general printing service was developed as RESTful web service;

- A mobile application for the Android platform was designed and deployed: It was capable of interfacing with handheld RFID readers and designed for use on the shop-floor;

- A multi-user web application was designed and deployed for desktop use for process management and for showing dashboards based on data obtained from the automatic tracking system;

- Integration with enterprise systems (mainly MES of establishment) through web services was developed;

- The specification and implementation of company user authentication and authorization mechanisms to ensure data security were implemented.

\subsection{Technological Impact on Processes}

The processes improvements were defined according to the main features of the analyzed detection technologies (e.g., RFID, Beacon, RuBee) and to the easiness in developing and deploying information systems to support such revised processes for those technologies (e.g., availability of middleware solutions, of software development kits, of open standards).

The analyzed processes were revised and modeled according to the chosen technologies: An improved version of the MRO process (i.e., a to-be process) was created for each technology. In this way, it was possible to select the best alternative, also considering the impact that the tracking technology had on the processes flow. Once an improved version of the process was selected, the technological development was carried out in order to allow the digitalization of the process itself.

In the development of the solution, the main guidelines were (a) a low impact in the operators' daily activities, (b) generalization of developed components to enhance high re-usability in other plants and (c) the scalability of the solution. 
Once RFID technology was selected based on cost-benefit analysis, other process concerns were assessed: The demand for precision in identifying the parts in some tasks resulted in greater use of handheld devices changing the operativeness on these activities. The use of a RFID handheld reader in the most critical points of the process (identified by the analysis) made it possible to meet the most stringent requirements of reliability in reading compared to fixed readers placed on the gates.

From the implementation point of view, this was translated into a greater demand for software logic to support operations with handheld readers: For this reason, a handheld reader to be linked with an Android or iOS smartphone via Bluetooth was chosen. The proposed technological solution allowed the creation of a solution more scalable and reusable for an extended enterprise context. In Figure 3, the steps followed to design and implement the technological innovation are resumed and represented.

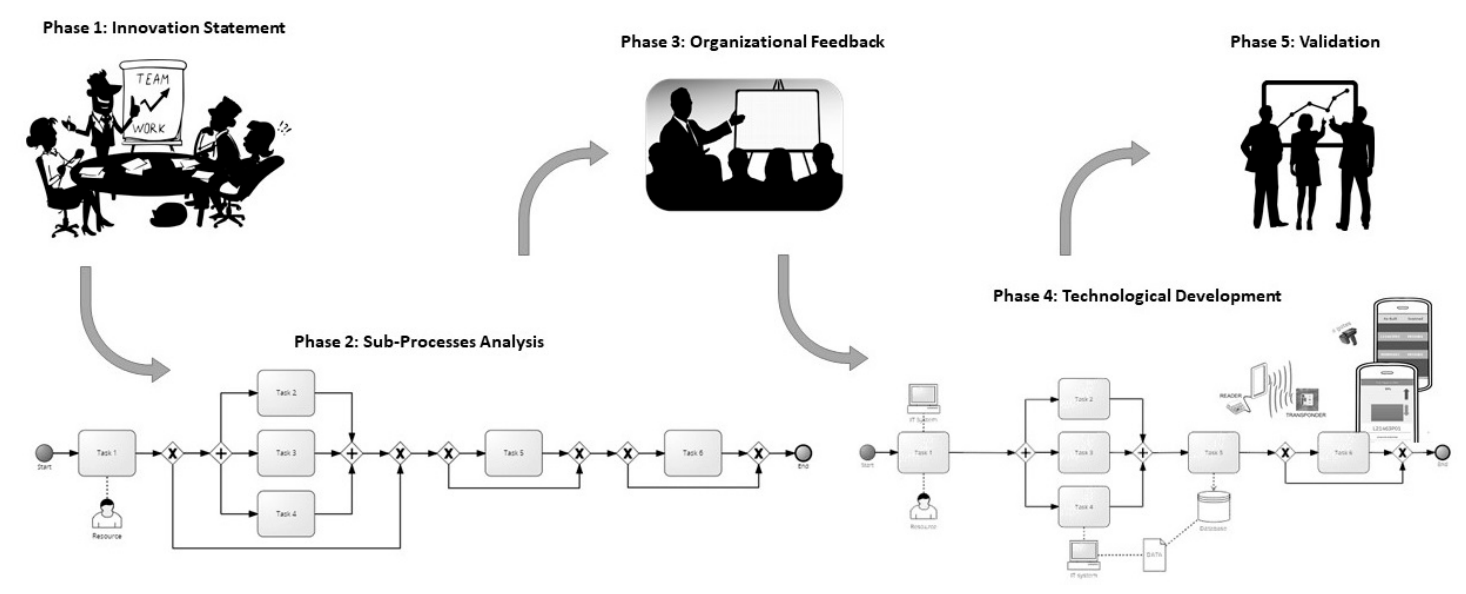

Figure 3. Steps followed toward innovation.

\section{Discussion}

The described results were developed with the objective of achieving a radical improvement in manufacturing process performance through design, implementation and field test of both the developed methodologies and technologies. Such an innovation falls within the Industry 4.0 paradigm, pointing at strengthening the collaboration between the shop floor and the engineering company departments of design and production. As also previous cited, the MRO processes, especially those concerning unplanned maintenance, are more variable than other production processes, because the activities depend on the arrival conditions of engines and components. Therefore, it is of great importance to have the chance to get, from the shop floor, accurate and up-to-date information about the (physical) parts constituting engines and components, regarding both their localization and their processing status. The systematic availability of such information would allow the enterprise to have an improved control on work order and process activities. Furthermore, as stated in the literature [24], also in the analyzed case, it is significant to have a widespread coverage of product information and work orders along the whole shop floor, by reporting data with accuracy and promptness in order to allow process execution as quickly and efficiently as possible.

In the analyzed case, the implementation of a technological solution for the part tracking in the MRO process enhanced the product data distribution within the factory and it made such data available when they are needed. Consequently, the whole MRO process was sped up and the final quality of delivered engines was enriched.

In detail, during the validation phase of the study, three indicators emerged. The values, which are represented in Table 3, were obtained by normalizing the annual data provided by the company (which cannot be disclosed) with the data of the experimentation carried out on a portion of the engine. Some lessons learned, which would be useful as feedback on the indicator values, are also proposed. 
Table 3. Performance indicators.

\begin{tabular}{|c|c|c|c|}
\hline Indicator & Description & Expected Value & Lesson Learned \\
\hline $\begin{array}{l}\text { Time spent in } \\
\text { searching for } \\
\text { parts }\end{array}$ & $\begin{array}{l}\text { It is the time dedicated to } \\
\text { the search of an item } \\
\text { along the whole process } \\
\text { in order to check the } \\
\text { status or make } \\
\text { operations. }\end{array}$ & $\begin{array}{l}-60 \% \\
\text { (the value is obtained by } \\
\text { confronting the time spent in } \\
\text { searching for parts on the } \\
\text { experimental sample in relation } \\
\text { to the equivalent mean value } \\
\text { given by a search without RFID) }\end{array}$ & $\begin{array}{l}\text { It becomes influent when it deals with } \\
\text { working in large factories, with long } \\
\text { production lines, located even in } \\
\text { different buildings and with many } \\
\text { moving parts. In this context, the } \\
\text { ability to quickly find a single } \\
\text { component every time it is required, } \\
\text { guarantees time saving. }\end{array}$ \\
\hline $\begin{array}{l}\text { Parts with } \\
\text { automated } \\
\text { tracking }\end{array}$ & $\begin{array}{l}\text { It is the number of parts } \\
\text { for which the tracking } \\
\text { has been automatized. }\end{array}$ & $\begin{array}{l}+40 \% \\
\text { (the value represents the } \\
\text { percentage of the parts of the } \\
\text { single engine whose positions } \\
\text { are traced by RFID: In fact not } \\
\text { all the parts of the engine are } \\
\text { labelled with RFID tags, but } \\
\text { only those of the most critical } \\
\text { and overhauled assemblies. The } \\
\text { plan is to extend automatic } \\
\text { tracking to all parts) }\end{array}$ & $\begin{array}{l}\text { Such a feature can become critical } \\
\text { when moving parts increase up to one } \\
\text { thousand units, like in the aerospace } \\
\text { (aircraft are made from thousands of } \\
\text { structural parts, some as small as a } \\
\text { playing card) and automotive (over } \\
\text { thirty thousand parts) industries. This } \\
\text { feature guarantees a detailed control } \\
\text { on production flows compliance, } \\
\text { foreseeing errors and mismatching, } \\
\text { beyond simplifying the identification } \\
\text { of any bottlenecks. }\end{array}$ \\
\hline $\begin{array}{l}\text { Average lead } \\
\text { process time }\end{array}$ & $\begin{array}{l}\text { It is the time needed to } \\
\text { develop all the activities } \\
\text { related to the } \\
\text { analyzed process. }\end{array}$ & $\begin{array}{l}-25 \% \\
\text { (The value is obtained by } \\
\text { normalizing the average lead } \\
\text { time of the sample on which the } \\
\text { experiment was carried out in } \\
\text { relation to the actual data for the } \\
\text { whole engine) }\end{array}$ & $\begin{array}{l}\text { Since this one is strictly linked with } \\
\text { the reduction of time required for } \\
\text { documentation, the elimination of } \\
\text { errors and misalignments, the break } \\
\text { down of missing part search times } \\
\text { and the systematization of the flows } \\
\text { control, this implies a drastic } \\
\text { reduction of each product flow time } \\
\text { and a consequent cost reduction. }\end{array}$ \\
\hline
\end{tabular}

Furthermore, a set of benefits are specified and are related to the potentiality of the developed solution:

- Digital data and real data misalignment avoidance: The availability of such a solution provides a complete and correct picture of the issues related to the activities performed (i.e., parts, status, position, time) and also on the information system. Real and digital data are entirely aligned. Each time a piece of information is needed, with a high level of confidence, the one available on the system corresponds with the concrete situation.

- Easier extension of the solution in the whole supply chain: Given the modularity and simplicity of the components, such a kind of integrated solution can be easily replicated and implemented in other contexts. This constitutes an opportunity to integrate the whole supply chain in the view of tracing and control the external repair of the parts for a more complete monitoring of all the steps.

At the end, the logic in the design of the solution aims to allow its replication in many different industrial contexts. The RFID is a standard, so the integration with the middleware is easily generalizable, and the database query services have been developed for the aerospace context, but the micro-service architecture is highly customizable and declinable in other use cases. Further studies are needed for different industrial contexts. RFID is not the only tracking technology that can be considered and the value added coming from its application is strictly linked to the specific business case. Different tracking technologies could be more appropriate for other business, depending on the nature of the materials handled, the configuration of the processes and the factory layout. At the same time, the usability of innovative solution has to be compared with the potential internal resistance to change. Furthermore, in this specific case the company had its own ICT system already in place. Otherwise, the suggested methodology would be integrated with further evaluations and best practices.

Comparing with existing studies in the literature, the proposed solution enlarges the state of art and, in some cases, it is aligned with the observed approaches and benefits. Lee et al. [21] highlighted 
the impressive results obtained with the use of PLM in the design phase of the aircrafts, arguing the great potential of its utilization also in the MRO processes, because of the long lifespan of aircraft. The main issue is the difficult access to information when it is needed, especially in the MRO processes, where the lack of data availability at the right moment leads to delays in deliveries [25]. Zhu et al. [28] classified the knowledge involved in MRO services into a hierarchical model, which distinguishes between different types of knowledge, like the reference knowledge that comprehends historical data related to process flows, and WIP knowledge, which is the knowledge managed by the solution proposed in this paper. Such a solution goes over the job card management methodology introduced by Geng et al. [32] by integrating the job cards with the management system. RFID technology for part tracking was already used in manufacturing for different purposes, like anti-counterfeiting [29], supply chain and asset management [30], WIP tracking [26] and resources management in aerospace maintenance operations [31]. The solution proposed in this paper integrates the RFID part tracking technology in the whole MRO enterprise management system, comprehending the outsourcing operations.

\section{Conclusions}

Starting from a literature analysis on the Industry 4.0 paradigm and the consequences of its implementation in the manufacturing industry, based on companies' increasing need for digitalization to improve quality and speed-up execution time, this paper analyzed the implementation of a parts tracking system solution in an aerospace company dealing with MRO processes. In detail, the paper aimed to understand how the digitalization in the MRO process could guarantee improvement in MRO knowledge management and, consequently, in the control of activities.

MRO processes are extremely hard to manage due to the complexity of the products involved and to the great number of laws and regulations to manage. Furthermore, such processes are extremely variable and dependent on the engine arrival conditions. The uncertainty about the process flows makes it very important that the work-in-progress knowledge is maintained in order to allow complete and exhaustive control on operations and to avoid bottlenecks. Furthermore, because of the quantity of parts moved, a proper MRO knowledge system must be able to manage reference knowledge in order to avoid misalignment between digitalized and real data.

The solution presented in this paper is structured to enable managers to make strategic decisions to improve efficiency of processes and, consequently, the reliability of the outputs of MRO activities, fostering the growth of the MRO market and meeting customers and users expectations. Furthermore, the proposed solution may prove how the implementation of the Industry 4.0 paradigm could give real advantages in managing complex processes and products. The implementation of the described solution requires companies to carefully evaluate the processes and IT system on which it is applied and integrated. The technological investments needed to sustain the required hardware and software has to be an object of evaluation also. A strategy of change management for catching on the new practices, due to the introduction of this solution, is also required in order to reach better diffusion with a lower impact.

The limit of this research is that the solution has been designed on a specific case. Further research has to be carried out in order to identify more generic best practices for the implementation of Industry 4.0 paradigm in designing technology solutions for manufacturing enterprises.

Author Contributions: Conceptualization, M.E., M.L., A.M., L.Q.; data curation, M.E., M.L.; funding acquisition, M.L.; investigation, M.E., M.L., A.M., L.Q.; methodology, M.L., A.M.; software, A.M., L.Q.; writing一original draft preparation, M.E., M.L., A.M., L.Q.; writing-review and editing, M.E., A.M.

Funding: This research was funded by the Italian Ministero dell'Istruzione, dell'Università e della Ricerca through call PON R\&C 2007-2013, Project SPIA (Innovative Aeronautic Primary Structures), Code PON03PE_000067_3.

Conflicts of Interest: The authors declare no conflict of interest. 


\section{References}

1. Stalnaker, T.; Usman, K.; Taylor, A. Airline Economic Analysis 2016-2017; Oliver Newman-Marsh \& McLennan Companies: New York City, NY, USA, 2017.

2. Cooper, T.; Smiley, J.; Porter, C.; Precourt, C. 2017-2027 Global Fleet and MRO Market Forecast Summary; Oliver Wyman-Mash \& McLennan Companies: New York City, NY, USA, 2017.

3. Uhlmann, E. Markt- und Trendstudie Maintenance, Repair and Overhaul 2011; Version 11-03-31; Schriftenreihe Märkte Kennen-Trends Nutzen: Berlin, Germany, 2011.

4. Uhlmann, E.; Bilz, M.; Baumgarten, J. MRO_Challenge and Chance for Sustainable Enterprises; Elsevier: Amsterdam, The Netherlands, 2013; pp. 239-244.

5. Manyika, J.; Chui, M.; Bughin, J.; Dobbs, R.; Bisson, P.; Marrs, A. Disruptive Technologies: Advances that Will Transform Life, Business, and the Global Economy; McKinsey Global Institute: New York City, NY, USA, 2013.

6. Stankovsky, S.; Ostojic, G.; Lazarevic, M. RFID Technology in Product Lifecycle Management. In Engineering the Future; Dudas, L., Ed.; InTech: Rijeka, Croatia, 2010; pp. 281-296.

7. Corallo, A.; Lazoi, M.; Secundo, G. Inter-organizational knowledge integration in collaborative NPD projects: Evidence from the aerospace industry. Knowl. Manag. Res. Pract. 2012, 10, 354-367. [CrossRef]

8. EFNMS. European Federation of National Maintenance Society. Available online: http://www.efnms.eu/ (accessed on 6 July 2018).

9. Vieira, D.R.; Loures, P.L. Maintenance, Repair and Overhaul (MRO) Fundamentals and Strategies: An Aeronautical Industry Overview. Int. J. Comput. Appl. 2016, 135, $21-29$.

10. Ng, T.J.; Wong, M.M.; Zhang, J.B.; Gan, O.P. RFID for MRO Work in Progress Tracking. In Proceedings of the IECON 2006-32nd Annual Conference on IEEE Industrial Electronics, Paris, France, 6-10 November 2006; pp. 4779-4784.

11. Potti, G. Fabbrica 4.0-La Rivoluzione Della Manifattura Digitale; Il Sole 24 ORE: Milano, Italy, 2015; pp. 9-11. Available online: http://www.confindustriasi.it/fabbrica4.0/Fabbrica40.pdf (accessed on 6 July 2018).

12. Gregor, M.; Medvecky, Š.; Matuszek, J. Digital Factory. Product. Innov. 2006, 2, 38-42.

13. Gregor, M.; Medvecky, S.; Matuszek, J.; Stefánik, A. Digital factory. J. Autom. Mob. Robot. Intell. Syst. 2009, 3, 123-132.

14. Berends, H.; Vanhaverbeke, W.; Kirschbaum, R. Knowledge management challenges in new business development: Case study observations. J. Eng. Technol. Manag. 2007, 4, 314-328. [CrossRef]

15. Katila, R. New Product Search over Time: Past Ideas in Their Prime? Acad. Manag. J. 2002, 5, $995-1011$. [CrossRef]

16. Lazarevic, M.; Ostojic, G.; Cosic, I.; Stankovski, S.; Vukelic, D.; Zečević, I. Product lifecycle management (PLM) methodology for product tracking based on radio-frequency identification (RFID) technology. Sci. Res. Essays 2011, 6, 4776-4787.

17. Wang, K.S. Intelligent and integrated RFID (II-RFID) system for improving traceability in manufacturing. Adv. Manuf. 2014, 2, 106-120. [CrossRef]

18. Röglinger, M.; Pöppelbuß, J.; Becker, J. Maturity models in business process management. Bus. Process. Manag. J. 2012, 18, 328-346. [CrossRef]

19. CIMDATA. Product Lifecycle Management "Empowering the Future of Business", "A CIMdata Report" 2002. Available online: http://doc.mbalib.com/view/8cb8b763acd25742ed7e72ad9ac29d01.html (accessed on 6 July 2018).

20. Proud, S.; Wetzer, M. The Product Lifecycle Management Opportunity. 2003. Available online: http: //www.ascet.com/documents.asp?d_ID=2015 (accessed on 6 July 2018).

21. Lee, S.G.; Ma, Y.S.; Thimm, G.L.; Verstraeten, J. Product lifecycle management in aviation maintenance, repair and overhaul. Comput. Ind. 2008, 59, 296-303. [CrossRef]

22. Borsato, M. Bridging the gap between product lifecycle management and sustainability in manufacturing through ontology building. Comput. Ind. 2014, 65, 258-269. [CrossRef]

23. Wan, S.; Dongbo, L.; Gao, J.; Roy, R.; Tong, Y. Process and knowledge management in a collaborative maintenance planning system for high value machine tools. Comput. Ind. 2017, 84, 14-24. [CrossRef]

24. Vermesan, O.; Friess, P. Internet of Things_From Research and Innovation to Market Deployment, IERC Cluster Ebook; River Publishers Aalborg: Aalborg, Denmark, 2014. 
25. Udoka, S.J. The role of automatic identification (auto ID) in the computer integrated manufacturing (CIM) architecture. Comput. Ind. Eng. 1992, 23, 1-5. [CrossRef]

26. Huang, G.Q.; Zhang, Y.F.; Jiang, P.Y. RFID-Based wireless manufacturing for real-time management of job shop WIP inventories. Int. J. Adv. Manuf. Technol. 2008, 36, 752-764. [CrossRef]

27. Zhu, H.; Li, D.; Tong, Y. An Ontological Knowledge-Based System for Maintenance, Repair and Overhaul Services. Int. J. Digit. Content Technol. Appl. (JDCTA) 2013, 7, 76-84.

28. Zhu, H.; Gao, J.; Li, D.; Tang, D. A Web-based Product Service System for aerospace maintenance, repair and overhaul services. Comput. Ind. 2012, 63, 338-348. [CrossRef]

29. Choi, S.H.; Yang, B.; Cheung, H.H.; Yang, Y.X. RFID tag data processing in manufacturing for track-and-trace anti-counterfeiting. Comput. Ind. 2015, 68, 148-161. [CrossRef]

30. Holmström, J.; Kajosaari, R.; Främling, K.; Langius, E. Roadmap to tracking based business and intelligent products. Comput. Ind. 2009, 60, 229-233. [CrossRef]

31. Saygin, C.; Tamma, S. RFID-enabled shared resource management for aerospace maintenance operations: A dynamic resource allocation model. Integr. J. Comput. Integr. Manuf. 2012, 25, 100-111. [CrossRef]

32. Geng, J.; Tian, X.; Bai, M.; Jia, X.; Liu, X. A design method for three-dimensional maintenance, repair and overhaul job card of complex products. Comput. Ind. 2014, 65, 200-209. [CrossRef]

33. Quintana, V.; Rivest, L.; Pellerin, R.; Venne, F.; Kheddouci, F. Will Model-based Definition replace engineering drawings throughout the product lifecycle? A global perspective from aerospace industry. Comput. Ind. 2010, 61, 497-508. [CrossRef]

34. OMG. BPMN Specification. Available online: https://www.omg.org/spec/BPMN/2.0/About-BPMN/ (accessed on 6 July 2018).

(C) 2019 by the authors. Licensee MDPI, Basel, Switzerland. This article is an open access article distributed under the terms and conditions of the Creative Commons Attribution (CC BY) license (http://creativecommons.org/licenses/by/4.0/). 